Journal of Korean Powder Metallurgy Institute

Vol. 15, No. 6, 2008

\title{
Using Nanosecond Electron Beam to Produce Silver Nanopowder
}

\author{
M. E. Balezin, O. R. Timoshenkova, S. Yu. Sokovnin, Hi Min Lee ${ }^{a}$ and C. K. Rhee ${ }^{a *}$ \\ Institute of Electrophysics, Ural Branch RAS, 106 Amundsen St., 620216 Ekaterinburg, Russia \\ ${ }^{a}$ Korea Atomic Energy Research Institute, 1045 Daedukdaero, Daejeon, Korea, 305-353
}

(Received September 12, 2008; Accepted November 7, 2008)

\begin{abstract}
Experiments with a URT- 0.5 accelerator $(0.5 \mathrm{MeV}, 50 \mathrm{~ns}, 1 \mathrm{~kW})$ generating a nanosecond electron beam for irradiation of silver nitrate in various liquid solutions (water and toluene) were performed with the aim of producing silver nanopowders. A radiochemical reaction allows making weakly agglomerated pure Ag powders with particles of 10-15 nm and 30-50 nm in size by irradiation in toluene and water respectively. The injection of the nanosecond electron beam energy to the solution is optimal. As the absorbed dose increases, the output of the radiochemical reaction does not grow, but more agglomerated powders are synthesized.
\end{abstract}

Keywords : Nanosecond electron beam, Silver nanopowder, Radiochemical reaction

\section{Introduction}

Synthesis of weakly agglomerated silver nanopowders is important for making of nanostructured materials used in microelectronics, electrochemistry and synthesis of optoelectronic sensors, pigments, etc. [1].

Bactericidal properties of silver ions are of special importance since these properties silver nanopowders may serve as the basis for development of new classes of bactericidal preparations and various pharmaceutical substances in medicine and agriculture $[2,3]$.

Methods used for synthesis of silver nanopowders can be classified by their production techniques. Today the basic methods for production of silver nanopowders and their aqueous suspensions are chemical methods. In this case, it is important to provide conditions facilitating the formation of fine silver particles.

The most widespread chemical methods is reduction of silver particles from aqueous solutions of silver salts in the presence of stabilizers [4-6]. The reducing agents are hydrogen and hydrogen-containing compounds such as tetrahydroborates $[4,7]$ and citrates of alkali metals [8], hypophosphites, alcohols [9], organometallic compounds [10]. Silver nanoparticles can be reduced either on the surface of pre-synthesized latex microspheres in the presence of a reducing agent or at the stage of monomer polymerization [11].

Physical methods include sputtering or mechanical grinding of bulky materials [12,13], photoreduction of silver salts [14], laser ablation of solids in liquids [15], and the use of electron beams [16].

The chemical methods have some drawbacks such as the influence of the concentration of the starting components on the progress of the reaction and the post-effect showing up as the coagulation of particles in the solution. Coagulation can be suppressed in the physical methods by addition of surfactants.

The greatest interest among the physical methods is attached to the use of electron beams since it was found that nanopowders with particles $10-60 \mathrm{~nm}$ in size can be produced at a relatively small fluence of electrons $\left(2 \cdot 10^{13}-3 \cdot 10^{15}\right.$ particles $\left./ \mathrm{cm}^{2}\right)$ [16]. As the

*Corresponding Author : [Tel : +82-42-868-8551; E-mail : ckrhee@kaeri.re.kr] 
electron fluence increases, the particle size diminishes unlike in the chemical methods when the increase in the reaction time leads to the growth of the particle size.

Nanosecond repetitive accelerators [17] allow a rather simple control of the exposure of reaction products and, with this in mind, we decided to study the possibility of producing nanopowders with the use of these accelerators.

\section{Description and Experimental Results}

Experiments on irradiation of solutions of silver nitrate in different liquids by a nanosecond electron beam from an URT-0.5 accelerator $(0.5 \mathrm{MeV}, 50 \mathrm{~ns}$, $1 \mathrm{~kW}$ [18]) were performed with the aim of producing silver nanopowders.

The following silver nitrate solvents $(0.3 \mathrm{~g}$ per 10 $\mathrm{ml}$ of the solvent) were studied:

1) Distilled water;

2) Toluene with addition of ethylene glycol (0.3 $\mathrm{ml})$ and ethyl alcohol (0.3 ml);

3) Ethyl alcohol;

4) Isopropyl alcohol;

5) $10 \%$ ammonia solution;

6) Isopropyl alcohol with addition of $2 \mathrm{ml}$ of a $10 \%$ ammonia solution.

The solutions were poured into a Petri dish so that

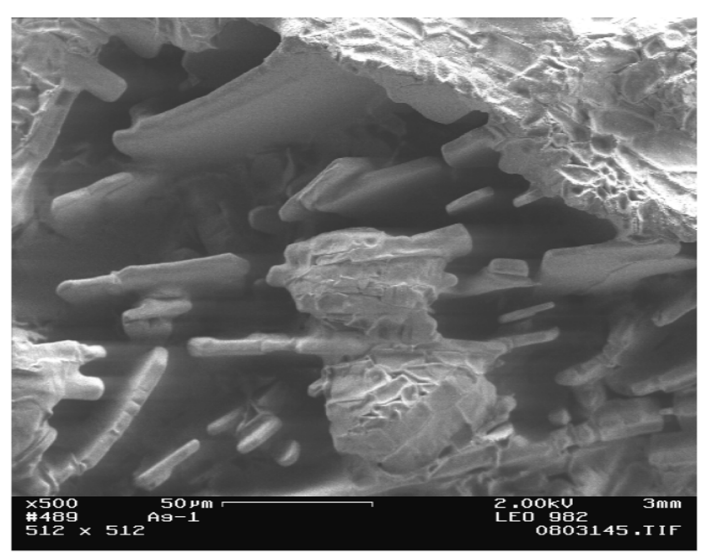

Fig. 1. SEM photograph of foam on the aqueous solution. the liquid layer was not more than $1 \mathrm{~mm}$ thick. The accelerator operated at a frequency of 10 pps for irradiation of the samples and the absorbed dose on the liquid surface in one minute was $0.36 \mathrm{MGy}$. The level of the doses was chosen considering the data of the study [16] since the design value of the absorbed dose at the lower limit of the fluence was about 0.6 MGy.

The following methods were used for examination of the materials:

- The specific surface of the powders, $S_{\mathrm{S}}$, was measured by the BET method on a TriStar 3000 V6.03 analyzer.

- The chemical composition of the powders was determined and the X-ray diffraction analysis was performed using standard methods on a D8 Discover X-ray diffractometer.

- The microscopic analysis was made in LEO-982 scanning electron microscope with EDX firm RONTEX and transmission electron microscope JEM-200.

It should be noted that the silver reduction reaction was vigorous in all the solvents, especially in the aqueous solutions.

Upon irradiation of the aqueous solutions some reaction products emerged to the surface as foam, while the others precipitated. The foam had a layered structure (Fig. 1) and the precipitate contained a

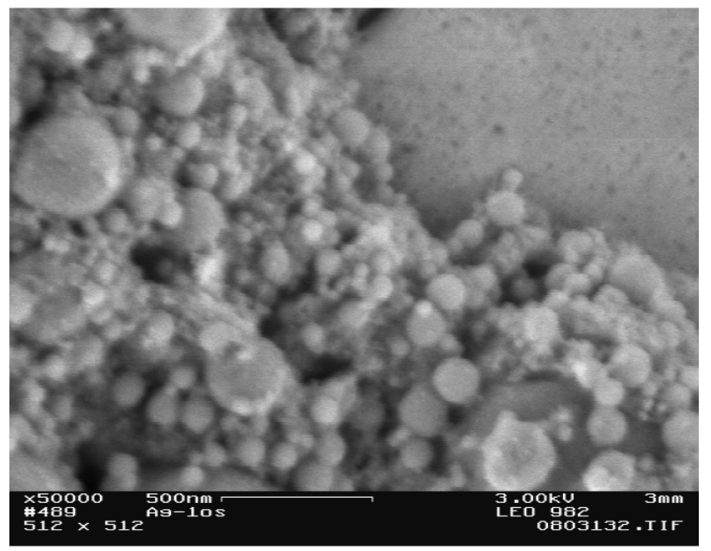

Fig. 2. SEM photograph of the precipitate in the aqueous solution. 


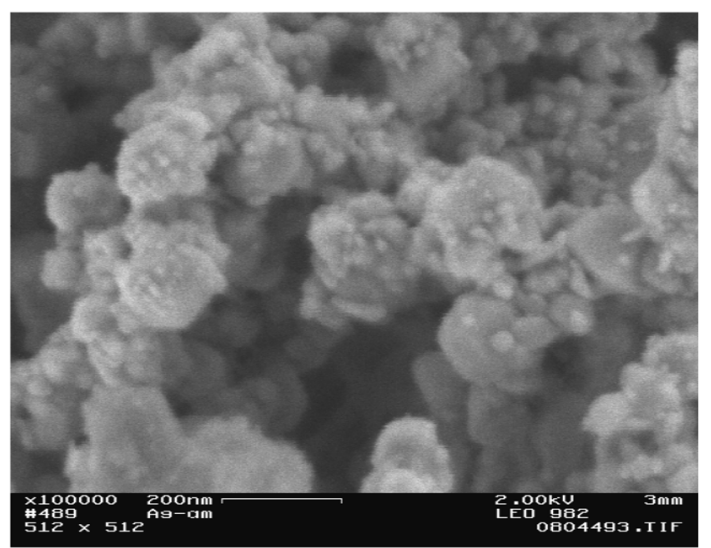

Fig. 3. SEM photograph of the nanopowder in the ammonia solution.

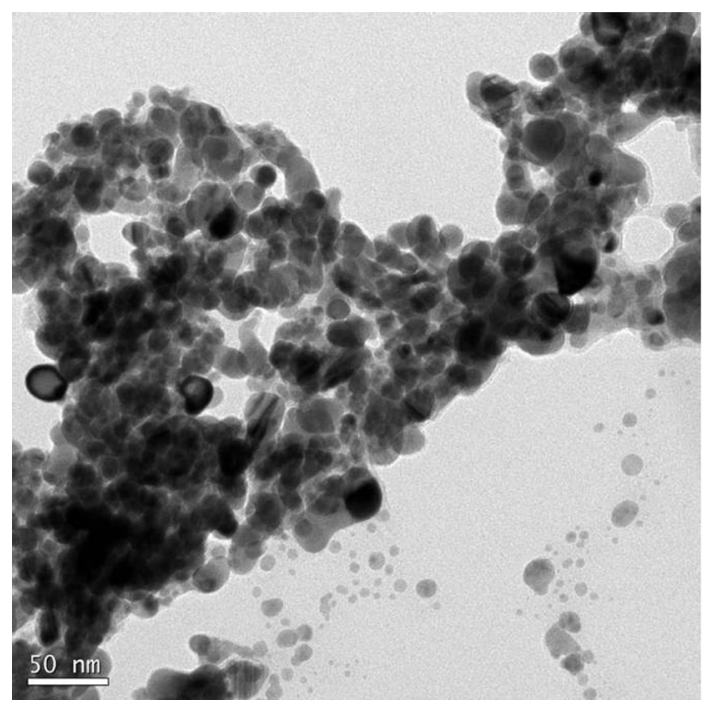

Fig. 4. A TEM photograph of synthesized Ag nanopowder (irradiation in toluene for 1 minute).

sufficiently agglomerated nanopowder (Fig. 2) with particles 30 to $200 \mathrm{~nm}$ in size. Foam was not formed and the powders were less agglomerated (Fig. 3) after irradiation in the ammonia solution. In any case the EDX analysis was achieved for the silver.

Weakly agglomerated silver powders with particles $10-15 \mathrm{~nm}$ in size (Fig. 4) were synthesized by irradiation of the toluene solution. It was found that the increase in the irradiation time from 1 minute to 10 minutes did not lead to the decrease in the particle size as was the case in [16] or the increase in the

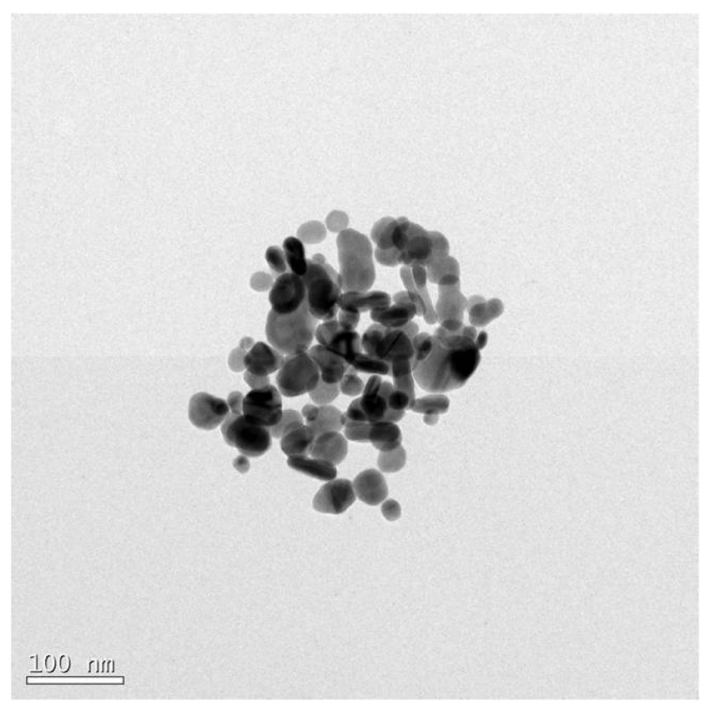

Fig. 5. A TEM photograph of synthesized Ag nanopowder (irradiation in toluene for 5 minute).

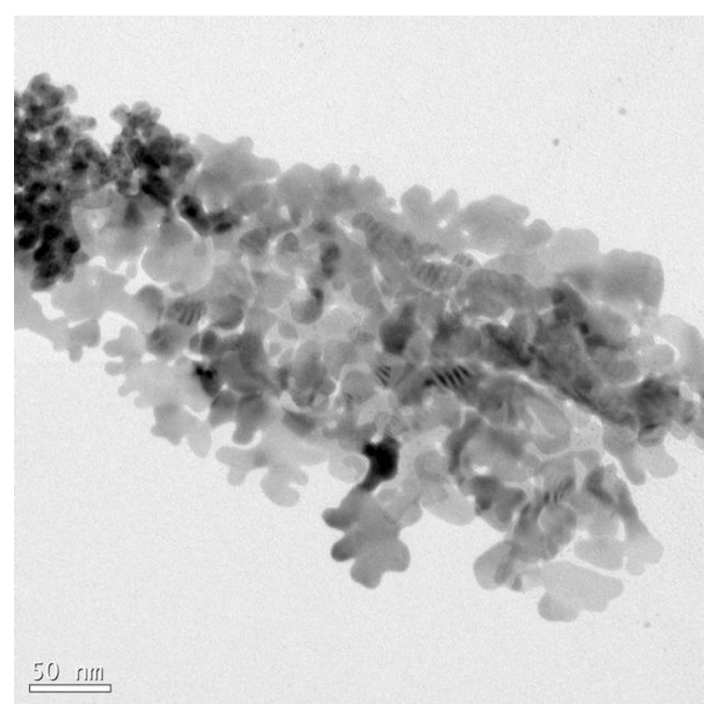

Fig. 6. A TEM photograph of synthesized Ag nanopowder (irradiation in toluene for 10 minute).

reaction yield; at the optimal dose and the irradiation time of 5 minutes (Fig. 5) the degree of agglomeration of the synthesized powders increased and junctions were formed between the particles (Fig. 6).

It is noticeable that the presence of ethylene glycol in the solution considerably complicated the preparation of the samples for the TEM examination. For this reason, the solution was irradiated in 


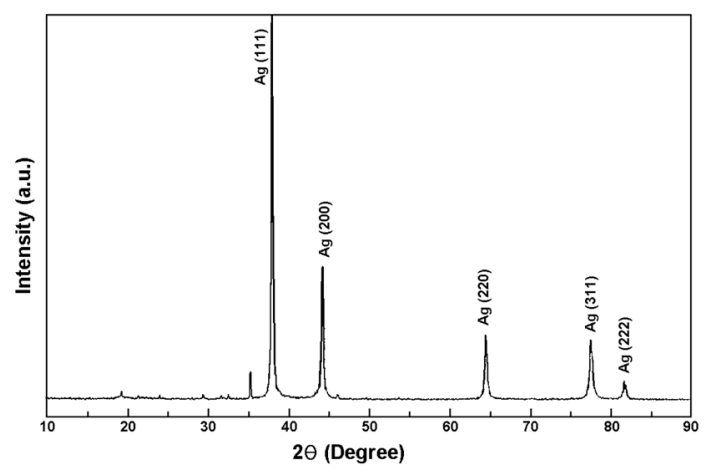

Fig. 7. X-ray diffraction pattern of the nanopowder in the isopropyl alcohol solution with ammonia.
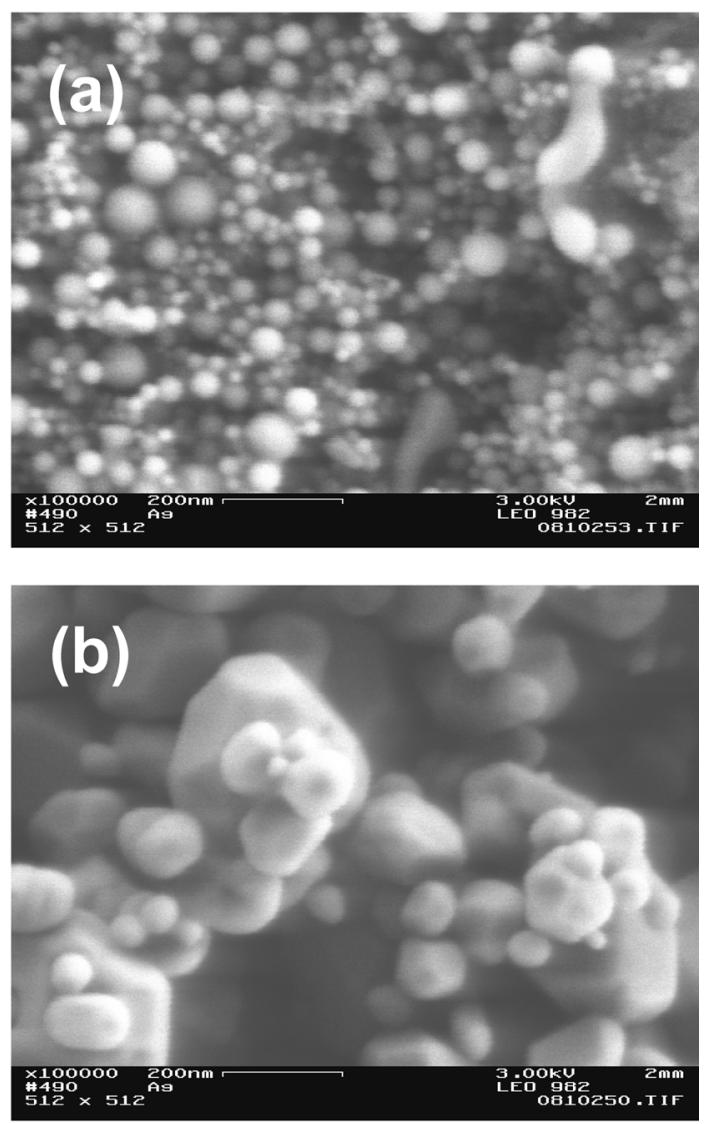

Fig. 8. SEM photographs of the nanopowder extracted from the upper part (a) and the bottom part (b) of the isopropyl alcohol solution with ammonia.

isopropyl alcohol, producing weakly agglomerated powders. An ammonia solution had to be added for good solubility of silver nitrate.
The specific surface of the synthesized of the nanopowder in the isopropyl alcohol solution with ammonia was $S_{\mathrm{S}}=3.97 \mathrm{~m}^{2} / \mathrm{g}\left(\mathrm{d}_{\mathrm{BET}}=140 \mathrm{~nm}\right)$.

The X-ray diffraction analysis of the synthesized powder showed that the sample had two phases, as show in Fig. 7. The first phase was an $\mathrm{Ag}$ in the face-centered cubic arrangement. The lattice spacing $a_{0}=4.086 \AA$ and the coherent scattering region (CSR) was about $56 \mathrm{~nm}$ in size. The Ag concentration was estimated to be $90-95$ wt.\% by an EDX analysis. The second phase $(\approx 5-10$ wt. $\%$ ) was an $\mathrm{AgNO}_{3}$ in orthorhombic lattice modification and the CSR was $130 \pm 30 \mathrm{~nm}$. This results correspond with the SEM photographs of the nanopowder synthesized in the isopropyl alcohol solution with ammonia (Fig. 8), in which the above two phases exhibit different particle sizes.

\section{Conclusion}

It is found that weakly agglomerated silver powders with particles $10-15 \mathrm{~nm}$ and $30-50 \mathrm{~nm}$ in size can be produced by exposure of a silver nitrate solution in toluene and water to an electron beam respectively.

The optimal input of the electron beam energy to the solution and a considerable increase in the absorbed dose did not lead to the increase in the reaction yield, but cause a larger agglomeration of the synthesized powders.

\section{Acknowledgement}

The authors wish to thank T.M. Demina, who measured the specific surface of the powders, Ph. D Y. R. Uhm for the electron microscopic examination of the samples, Ph. D A.I. Medvedev, who performed the X-ray diffraction analysis.

\section{References}

[1] E. M. Egorova and A. A. Revina: Kolloidny Zhurnal, 
64 (2002) 334.

[2] P. P. Jain and T. Pradeep: Biotech. and Bioeng., 90 (2005) 59.

[3] J. R. Morones, J. L. Elechiguerra and A. Camacho: Nanotechnology, 16 (2005) 2346.

[4] A. V. Vegera and A. D. Zimon: Izv. Tomskogo Politeknich. Univers., Tekhnicheskie Nauki, 309 (2006) 60 .

[5] C. Song, Y. Lin and Z. Hu: Nanotechnology, 15 (2004) 962.

[6] K.-S. Chou, K.-C. Huang and H.-H. Lee: Nanotechnology, 16 (2005) 779.

[7] Y. Lu, Y. Mei, M. Drechsler and M. Ballauff: Angew. Chem. Int. Ed., 45 (2006) 813.

[8] I. Sondi, D. V. Goia and E. Matijevic: J. of Colloid and Interface Science, 260 (2003) 75.

[9] Y. Wand, Y. Li, G. Zhang, D. An and C. Wang: Nanotechnology, 17 (2006) 3304.
[10] M. A. Yasnaya, A. A. Mikhalev and S. E. Khoroshilova: Vestnik SevKavGTU, 3 (2007) 58.

[11] V. P. Pileni: Pure Appl. Chem., 72 (2000) 53.

[12] T. Oates and A. Mucklich: Nanotecnology, 16 (2005) 2606.

[13] J. Lu, K-S. Moon, J. Xu and C. P. Wong: J. Mater. Chem., 16 (2006) 1543.

[14] P. K. Sudeep and P. V. Kamat: Chem. Mater., 17 (2005) 5404.

[15] A. V. Simakin, V. V. Voronov and G. A. Shafeev: Trudy Inst. Obschei Fiziki, 60 (2004) 88.

[16] K. A. Bogle, S. D. Dhole and V. N. Bhoraskar: Nanotechnology, 17 (2006) 3204.

[17] S. Yu. Sokovnin: Nanosecond Electron Accelerators and Radiation Technologies on their Basis, Ekaterinburg, UB RAS, (2007).

[18] Yu. A. Kotov, S. Yu. Sokovnin and M. E. Balezin: Prib. Tekh, Eksp, 1 (2000) 112. 